\title{
A Safety Tracking and Sensoring System for School Buses in Saudi Arabia
}

\author{
Samah Abbas ${ }^{1}$, Hajar Mohammed ${ }^{2}$, Laila Almalki ${ }^{3}$, Maryam Hassan $^{4}$, and Maram Meccawy ${ }^{5}$ \\ ${ }^{1}$ Management Information Systems Department, Faculty of Economics and Administration, King Abdulaziz University, Jeddah, Saudi \\ Arabia \\ 2,3,4,5 Information Systems Department, Faculty of Computing \& Information Technology, King Abdulaziz University, Jeddah, Saudi \\ Arabia
}

\section{Article Info}

Received April 29, 2019

\begin{abstract}
Technology can facilitate the daily movement of students to and from the schools. There are a number of IT systems that support the transportation of students, but the most important aspect is to ensure students' safety. Especially with increasing accidents of forgotten students who fall asleep inside school buses. Such incidents may result in asphyxiation or death. This paper presents a system that contributes to reducing the accidents of forgotten the students inside the school buses by enabling the parents to track their children. It includes installing a sensor system in school buses to protect the students during their daily journeys to and from their School by utilizing IoT technologies.
\end{abstract}

Sensor

Tracking School Buses

Temperature sensor

GPS

IoT

\section{Corresponding Author:}

Fifth Author, Departement of Information Systems,

Faculty of Computing \& Information Technology,

King Abdulaziz University, Jeddah, Saudi Arabia,

Email: mmeccawy@kau.edu.sa

\section{Introduction}

IoT technology has found wider use in our daily life. This technology uses a system of connected devices and sensor with internet via less or without human interaction. It helps in providing a good economy, comfortable, and convenient life [1]. Moreover, it helps in ensuring our safety and security, like surveillance cameras installed in public places. Some of these cameras use in schools for protection for the prevention of accidents, crime, and disasters. Recently, IoT technology has come to be used to solve several issues in transportation, such as at airports, which seek to provide good customer service [2]. In addition, it solve different issues in the educational environment, especially the problem of providing the students' safe transportation to and from their schools every day; a matter over which the parents of the students feel very much concerned.

There is a continuing series of painful accidents caused by the lack of care by drivers in ensuring that all the students who board the buses actually go to their schools. Some students fall asleep on the school bus and do not accompany their classmates to school. They are forgotten inside the bus for hours [3]. The child left alone inside the bus may develop tension, anxiety, and fear, which may affect the child's psychological state in the future. The child may develop claustrophobia (the phobia of closed places) main concern. Also, the child may suffocate, which may harm the child's health by causing injury or diseases such as asthma, and, in critical cases, may even cause death. Recently, the last incident in Saudi Arabia when a second-grade student was forgotten while he was sleeping in the back seat for long hours, resulted in asphyxiation and death [4]. There was another tragic accident in 2010 in which a young fouryears-old girl died inside the school bus in another Arab state [5]. Therefore, systems based on sensing and tracking technologies can be used in school buses to prevent such accidents [4]. 
There is a need for tracking and sensor system that combining GIS, GPS, SMS, which can be implemented as a mobile application for the school bus. In this paper, the researchers explore the needing of tracking and sensor system in the school bus in Saudi Arabia and suggest a combination system that can be applying in mobile of drivers, parents, and school.

\section{Related Work}

The intense around the world in creating effective ways by use of technology to ensure that the students who fall asleep or otherwise get trapped inside school buses are not forgotten there and suffer the problems of asphyxiation or death is illustrated by the numerous studies on this topic. Some of the studies are on using technologies to develop the methods for tracking the schoolchildren to ensure their safety on board the school bus. For instance, the study of [6] proposed a system by using Embedded Linux Board and Android method for providing a real-time system to track and monitor the school bus and additional LPG Gas leakage sensor MQ6 and temperature sensor to detect and prevent fire hazard inside the school bus.

However, some studies focused on providing a system just for tracking the children when they go the school. For example, a study of [7] was about developing a smart bus system that would notify the parents, the school, and the drivers. The system, in addition to allowing the parents to notify the school if on a day their child would not be attending the school, would enable the parents to track the bus on the GPS in real time using an android mobile application. In addition, two of the studies focused on providing tracking method for students by using Radio Frequency Identification (RFID) technology. One of them combined RFID with Global Positioning System (GPS), which is a satellite-based navigation system that is used in determining an object's position on the earth [8]. The two systems RFID and GPS linked with the General Packet Radio Service (GPRS) that connects to the application in order to notify the parents. Yet another used the two different tags of RFID (readers of which are installed on the school bus and the receiver implemented by using a specific card). This card would be placed in the student's schoolbag for recording the events and log the data such as the date and time the student enters and leaves the bus. All of the data would be saved directly on the server and also sent to the parents. This integrated system provided a solution for monitoring children while on their way to and from school by school bus without the driver's intervention [9], [10]. In our opinion, using the card for detection is a good way unless a student forgets to place the card in the schoolbag. Other solutions were suggested such as in [9], a study proposed a system for a smart and safe school bus. It used sensors to monitor the increase in carbon dioxide level in the bus. If it increased beyond a certain limit, the system would open a window to prevent the injury or death of the student by asphyxiation.

In Saudi Arabia, we found a lack of procedures for ensuring the safety of students traveling on school buses. Hence, the lack of awareness about technology that can provide safety and protection for the students inside the buses. The school buses drivers in Saudi Arabia are not familiar with technology and they do not use it most of the time. Hence, it is essential to implement such systems and instruct bus drivers, parents, and school administrators about their use to provide safety and protection for students who use school buses.

The government of Saudi Arabia is working with consulting companies to implement some projects for scheduling or tracking school buses and students [11]. A study by two students of Taibah University [12], in their study, proposed a mobile Android application suitable for tracking buses of Taibah University, their routing, and scheduling. The system could be useful for the bus drivers and the students of the University. This application provided GIS, GPS, notification system (SMS \& GSM), arrival time, and dynamic maps. Another study suggested a smart bus system to optimize the bus routes, pick up and drop off points for students and notification and feedback system from excused or absent students for the students of Taif University [13]. Although there is a lack of technology for tracking school buses in Saudi Arabia, there are some technologies that are used in the Hajj buses for tracking and controlling the pilgrims such as Study [14]. This study proposed an RFID-based system using, which connected with the pilgrims' buses for supervising, tracking and controlling the pilgrims and their buses.

However, there is still a need for tracking and sensor system for the school buses, which combines GIS, GPS, and SMS and is suitable for implementation as a mobile application. In this paper, the researchers explore the requirements of a tracking and sensor system in the school buses in Saudi Arabia and suggest a composite system that can be implemented on the mobiles of the parents, drivers and the school. The question here is how to provide safety and protection, especially for young school children who travel to and from home and school on school buses? How can we minimize the possibility of suffocation or death inside the school bus? How can the system be made simple and easy to use? 


\section{Data Gathering Phase}

To study and explore the research problem, we gathered the information from our target sample. In this study, we used qualitative and quantitative research methods for collecting data to discover the real situation of the school buses in Saudi Arabia. The questionnaires were distributed to parents and school administrators. Individual interviews of school bus drivers were used as sources of data/information from our sample of private schools and educational institutions. This included kindergartens, elementary, intermediate and secondary schools that provide bus service to their students. The objectives of using the questionnaire were, (a) To assess the current situation of the school buses in Saudi Arabia. (b) To measure the needs of the parents to track their children when they ride the school bus. (c) To assess the importance of providing protection for the students inside the school bus. (d) To gain more future users for the system we would produce from the sample. (f) To gather more information for better understanding our research problem and to identify our system requirements.

\subsection{Questionnaire}

Our questionnaire was distributed electronically to reach as many participants among our target sample as possible. We made two questionnaires one for school administration and the other for students' parents. First, we asked the participants a common question about the grade level of children using school buses. The subsequent questions focused on the importance of facilitating the safe movement of students between schools and their houses.

The responding answer from the school administrators was as following: Almost $66 \%$ of schools provided students transportation service by the bus while $34 \%$ not. In addition, $60 \%$ of schools did not have a supervisor in the bus responsible for ensuring safe entry and exit of the students while $40 \%$ had. That means there is a safety issue regarding school buses in Saudi Arabia. In addition, we asked the question to school administrators "What are the security and safety systems currently available on the bus to protect the students?". The results show 39\% have a fire alarm system, $6 \%$ have a system to prevent suffocation. However, an alarming 63\% gave such answers as "There is no safety system in the buses", "I don't know if there is a safety system in buses", "No, I do not know that such systems exist for buses".

On another hand, we asked the parents, "Usually, how do you keep track of your children's arrival at school?" The responses showed that $47 \%$ of parents tracked their children's arrival at school in special circumstances by contacting the school, 63\% said they contacted the driver or the supervisor, 38\% said they did not track their child's arrival at school. We received other responses such as: "I have my own driver, I put a camera in the car and send them by myself ". The fact that a high percentage, which was $63 \%$, of parents, contacted the bus driver in special circumstances showed the need for including the bus driver in our proposed tracking system as shown in Fig. 1.

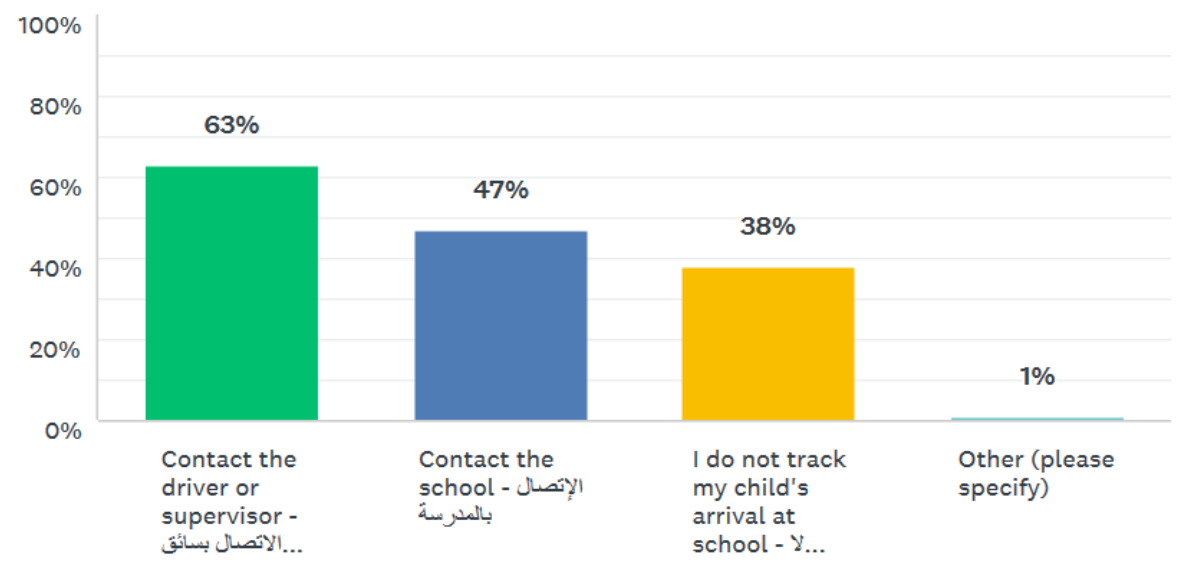

Figure 1. Ways to track children 
Based on widespread of mobile applications in all areas, around $88 \%$ preferred using the mobile application that enabled tracking the bus while $12 \%$ did not prefer that. Finally, we asked the parents about the systems they want to be implemented in the school buses and gave them the choice of several. "Fire alarm system" was chosen by $29 \%$, "A sensor system to prevent student detention inside the bus" was the choice of a very high 87\%, "Tracking system for the bus" was the highest choice with 92\%, and "System to prevent suffocation" was supported by $47 \%$ as shown in Fig. 2.

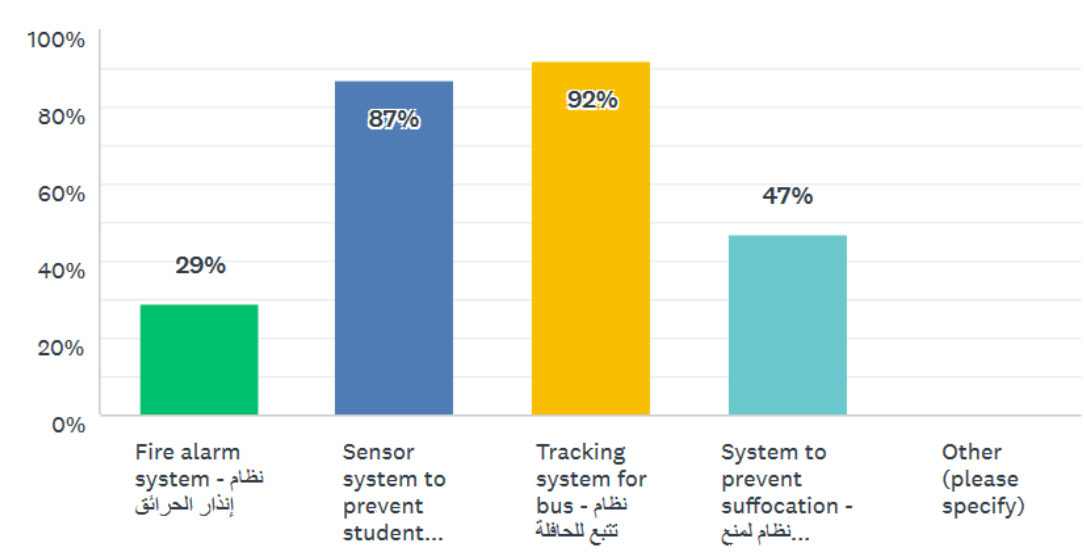

Figure 2: Systems want to be implemented in school buses

\subsection{Interviews}

We interviewed eight school bus drivers from different levels (Kindergarten, Elementary, Intermediate, and High school) of private schools in different cities in Saudi Arabia.

The aim of these interviews was to collect specific information for explaining the real difficulties and problems facing school bus drivers in Saudi schools. Also, to measure assess the ability of the drivers to act positively and manage emergency situations such as student's suffocation or fire inside the bus to ensure the safety and protection of the bus passengers, that is, the school students. The responses of the bus drivers strongly indicated the need for sensor systems that can send notifications (alerting messages) to bus driver's mobile phone in real-time if a student is forgotten and stranded inside a bus.

Furthermore, all the interviewees preferred checking the bus personally to ensure that no student remained on the bus. Some of the bus drivers preferred to have a supervisor to supervise the students on the school bus. Their rejection of the system was caused by difficulties that they faced in using mobile phone applications such as registering in the app, etc. Some of them that they may not trust the accuracy of the system, especially when it came to relying on the system to alert them about a missing student.

For getting more requirements for our proposed system, we interviewed two of the parents and school administrators. The parents strongly supported our proposed system that would help them to track their children. Also, the school administrators saw that it was important to have a system that provided safety and protection for their students when they used the school buses, particularly as the system could also provide them information about the absent students.

\section{The Proposed Safety Tracking and Sensoring System for School Buses}

The main objectives of the proposed safety tracking and sensor school bus system are as follows: (1) Ensuring that all the students who got on the bus got off the bus when they reached the schools or their homes. (2) Ensuring that the driver was alerted to the presence of a sleeping student on the bus, and to relieve the parents' anxiety about their children by including them in the system to follow their children.

This proposed system is developed as a mobile application that connected the school bus driver, the student's parents, and the school. This application would allow them to track the student using GPS during their journey 
on the school bus. Moreover, the system will notify the parents about the arrival of the bus from the school five minutes ahead of the time. It will enable the parents to inform the bus driver about the student's absence from the school. Therefore, the driver may not go to pick up the student and save that time. To ensure safety, a passive infrared sensor (PIR) has been added to the design, which is a non-contact temperature sensor that includes a sensing element interacts with own temperature, which varies as it absorbs or emits heat by radiation [15]. This PIR sensor used to detect from a remote location the temperature of a student's body inside the bus. This sensor will work when the school bus stop at its station in the school. If the heat of a student's body is sensed inside the bus, the system will send a continuous voice alarm message to the driver until the driver checks inside the bus. Thus, a student's life could be saved. The system also includes electronic supervision in real time rather than the traditional way of appointing a person to supervise the students inside the bus. Furthermore, the proposed system of being a mobile app will provide anytime usability and mobility. Also, the school can use the information that will be recorded in the system to know the number of absent students each day.

\subsection{System Analysis and Design}

As shown in Fig. 3, our safety tracking and sensor school bus system comprised of four actors. They were the school, the school bus driver, the parents, and the application. The first three actors have the following functional and non-functional requirements.

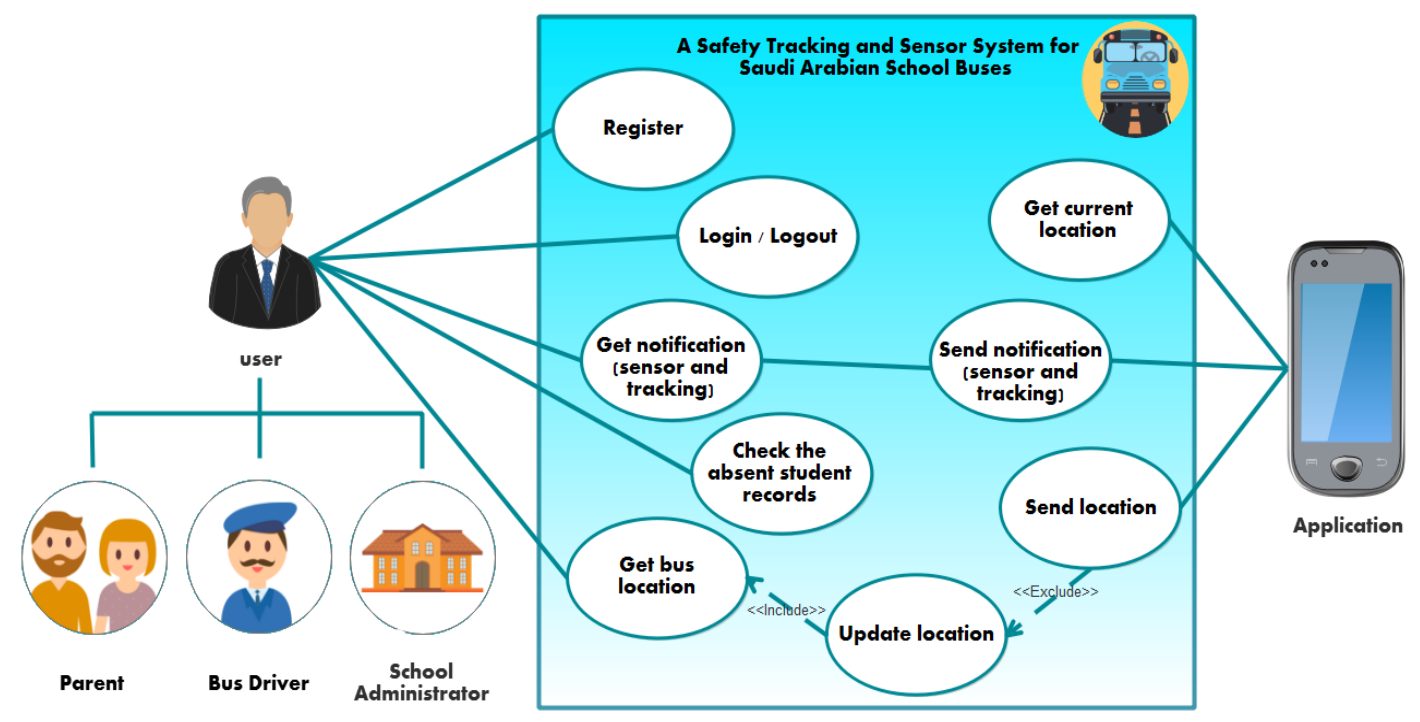

Figure 3.Tracking and sensor school buses system use case

The functional requirements in our safety tracking and sensor school bus system divide into two parts. First, for parent, driver, and school, which contain registering in the application, log in/log out, get a notification (sensor and tracking), check absence records of each student, and get bus location including updates of the location and distance from the location of the person seeking the information. Second, for the application, which contains get current location, send a notification (sensor and tracking), and send location.

In general, the software of our safety tracking and sensor system has three main components. First, the tracking system with the server that is provided by GPS (vehicle tracking system) using google maps. The second component is the GPRS/GSM service used to support the communication between the GPS system and a safety tracking and sensor application and database cloud servers. The third component depends on passive infrared (PIR), which is one of the infrared systems to detect heat radiated from a body. The required sensor installed inside the school bus will be linked by a program in Java programming language with our proposed application system that should be installed on the mobile phone of parents, driver, and school administrator. When the bus driver stops the school bus at the bus station, the PIR sensor will start searching for the presence of the human body. If there is a student left inside the bus, the PIR will make sound an alarm to alert the bus driver, at the same time sending an alert on the driver's mobile through the application. Moreover, the system 
will send a notification to the student's parent five minutes before the bus arrives at a student's home. The following diagram Fig. 4 shows clearly how our safety tracking and sensor system would work.

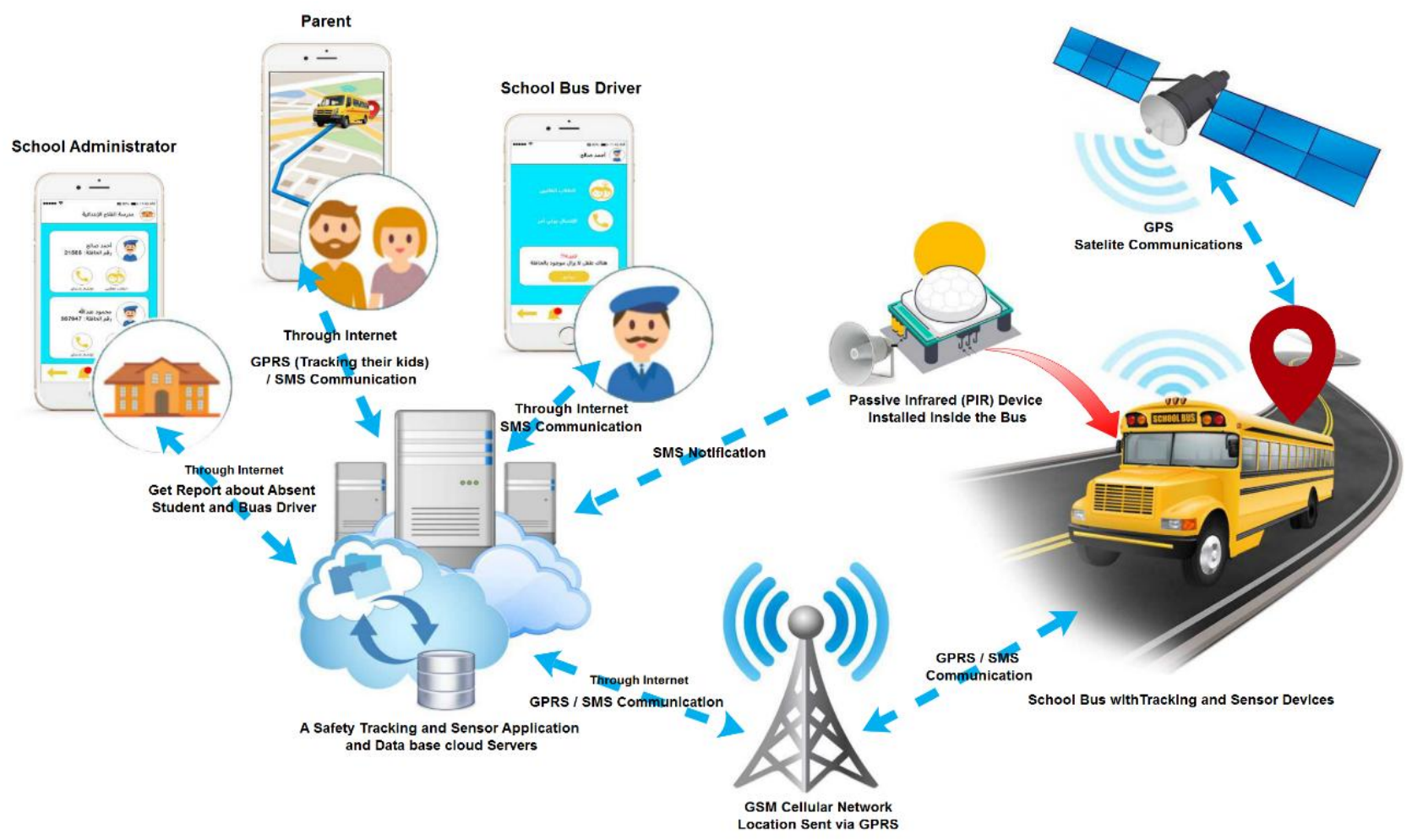

Figure 4: Diagram of safety tracking and sensor system

\subsection{User Interface Design}

The safety tracking and sensor school bus system begins with the login/sign up page (see Fig. 5). First, before the user can log in the user should sign in to the system, unless the user has previously signed in. In which case the user should directly login. The user should select his mission, driver, parent or school administrator. For example, if the user were a parent, the system will display a page that would allow the user to enter his information such as name, email and phone number. After the user fills the complete information, the system will confirm registration by sending a verification code to the user's mobile, when the user reenters the verification code correctly, the system would create the user's account. The bus driver and school administrator can sign up in the system in the same way as the parent. The bus driver should enter the required information like name, phone number, and bus number, and then confirm his registration. Similarly, the school administrator should complete his/her information and then confirm hislher registration.

The home page of parent interface has four sections: track the bus, inform the bus driver about the child's absence from school, call the bus driver, and add new bus driver if the driver changed. Fig. 6 shows us how parents can inform the bus driver about the student's absence. The parent can track the bus location by clicking on the "tracking bus" button, and then the parent would be able to see the current bus location as shown in figure 6 . The bottom bar has four buttons that allow the user to access the home page easily or change the settings and follow up the new bus alerts or log out. Moreover, the system will allow the parents to inform the bus driver if their children would be absent from the school, and also provide for making a call to the bus driver. In addition, when if the driver is changed, the parent would be able to add the new driver who would drive their children by searching the phone number of the new bus driver as shown in Fig. 7.

Moreover, the system will allow the parents to inform the bus driver if their children would be absent from the school, and also provide for making a call to the bus driver. In addition, when if the driver is changed, the parent would be able to add the new driver who would drive their children by searching the phone number of the new bus driver as shown in Fig. 7. Notice that the new driver must have an account in the system in order 
to be assigned by the parent as the new driver as a school bus driver who would be driving their children's school bus.
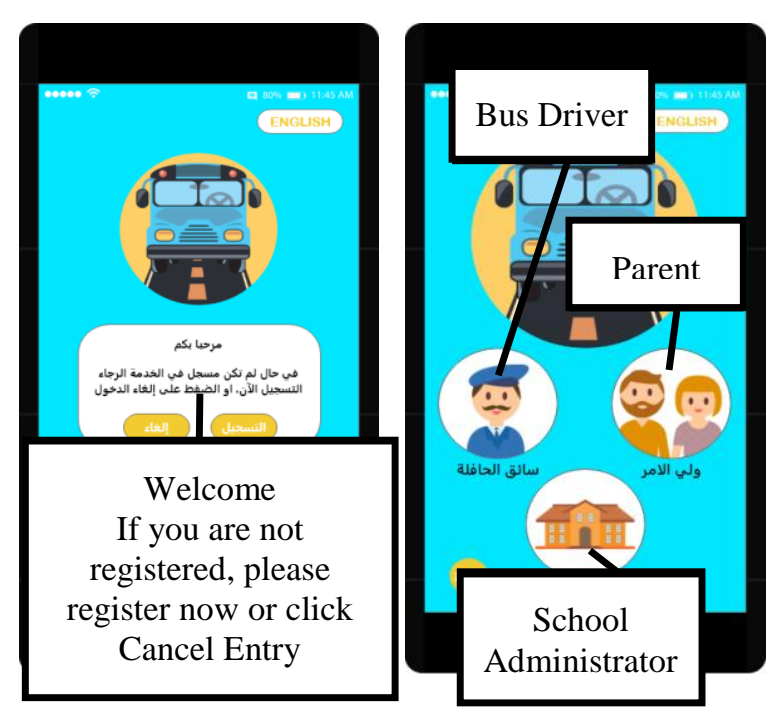

Figure 5: Sign up/sign in page

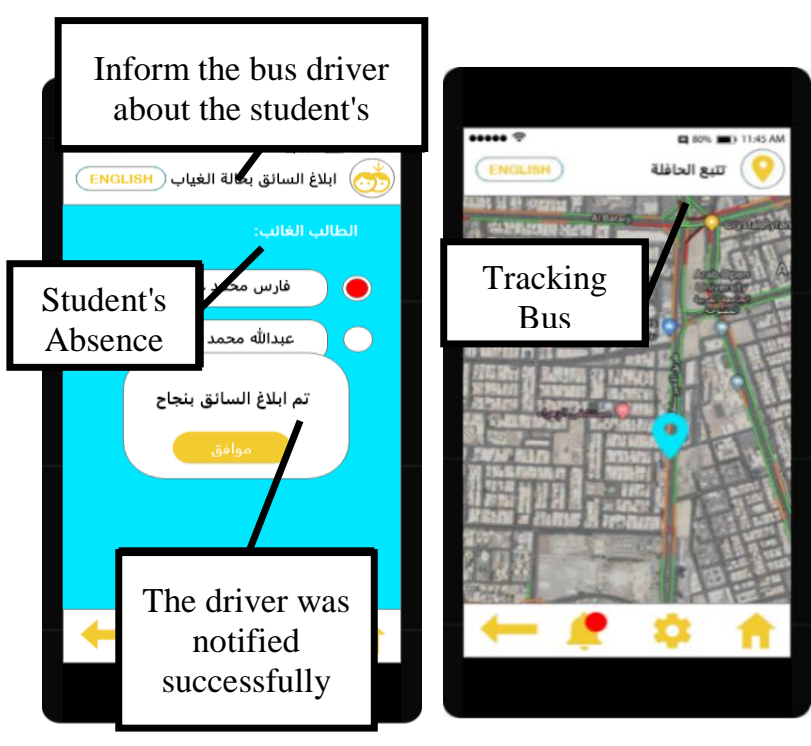

Figure 6: Informing the bus driver and tracking the bus

Fig. 8 represents the home page of the school bus driver. It has two sections: show absent students and call the students' parents. When the user (bus driver) clicks on the absent students' button, the system will restore all the information about absent students provided by the respective absent student's parents. The system would also send an SMS alert to the bus driver directly when the parents select absent button on their interface. The system would inform the bus driver through an SMS alert if there is a forgotten student inside the bus. The school bus driver would receive this alerting message when the sensor installed inside the bus detects the body heat of a person inside the bus. Therefore, this is the main feature of the system. The lower bar has the same functions as the parent interface.

The home page of the school administrator involves the list of bus drivers of the school and the facility for calling the drivers. The school administrator can follow up the absent students and store this record as shown in Fig. 9. Therefore, this list of school buses drivers will help the school to know about the absent students in each school bus and in each day.

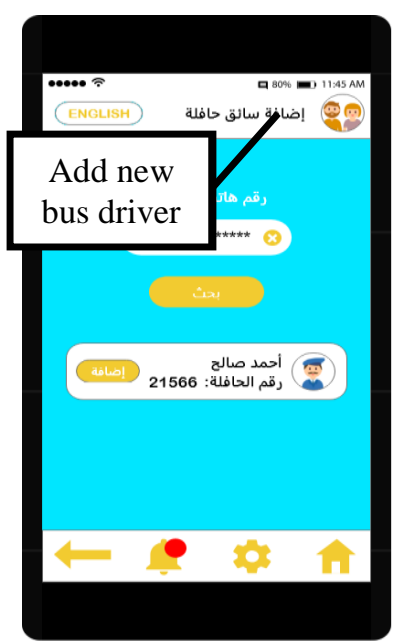

Figure 7: Add bus driver

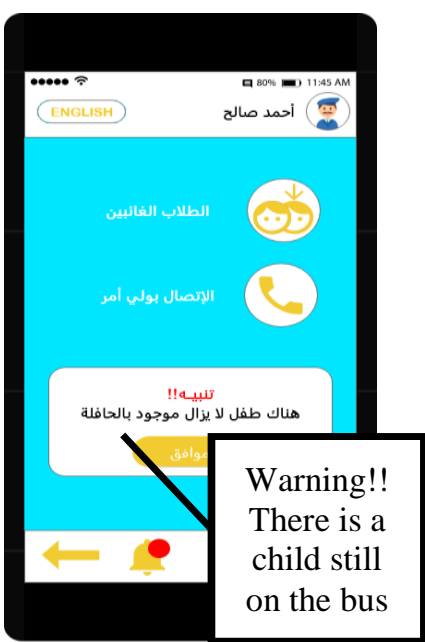

Figure 8: Bus driver interface

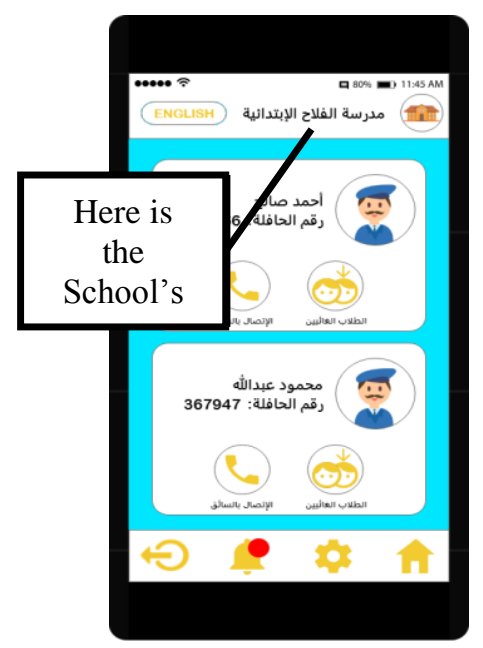

Figure 2 School administrator interface

The development of our mobile application is based on the Android platform using multi-software starting by 
using Java and XML of Android Studio to create the mobile application for the parent, bus, and school. Then, using XAMPP to run APACHE and SQL servers and using MYSQL for our system database. In addition, we use PHP for server-side programming and connecting android studio with a database. The monitoring and tracking system will be updated and stored in the servers built in the Cloud. For alerting, the application will notify the parent if the bus driver will not come and parent can send information about their children's absence. Our proposed system was simulated to test usability and design satisfaction. The testing and result of this simulation done in the next section.

\section{Testing and Results}

For evaluating the effectiveness of the simulated school bus safety tracking and sensor system, a usability testing was conducted on 150 people in the three schools in Jeddah, where the test sample includes school administrators, teachers who have children and bus drivers. They were asked about the fictional and nonfictional requirement of the application: ease to use of the application, clarity in registration steps, navigating between the application screens, and the ease of communication. We asked the bus drivers about the accuracy of the system when the system sent a notification of about absent student. The test results found that $65 \%$ of the users were satisfied; the users liked the interface design and did not notice any difficulties in navigating between screens. According to the parents' answers, using the application was easy, made them feel comfortable and assured about their children's safety when they started to track them using GPS tracking system. Moreover, the bus drivers gave a good impression of the sensor that integrated with the mobile application when will be implemented the PIR sensor inside the bus, which enables them to receive the notification about forgetting student inside the bus. In general, the users were satisfied with the system's usability, interaction, accuracy and security features.

\section{Discussion and Limitation}

The previous studies mentioned in the literature review section showed the importance of the system for ensuring the safety of children using school buses in Saudi Arabia, especially the safety of the young schoolchildren. Safety tracking and sensor school bus system helps to reassure parents about their children through the ability to track the bus location accurately by using GPS. The system enables the school to supervise the drivers and to follow up with the attendance records of students. Furthermore, enabling the drivers to keep track of the student left in the bus due to the efficient operation of the sensor and issuance of accurate alerts in the mobile application. These functions can contribute to reducing the cases of student forgotten in buses and reduce the number of injuries and deaths by suffocation inside the bus. Despite the positive results that appeared there are some obstacles that schools may face when using the system: (1) Acquiring and installing the PIR sensors in school buses is costly and complex. (2) Some drivers, given their age or limited IT skills, may resist using the new technology.

\section{Conclusions and Future Work}

Using emerging technology is possible not only for facilitating the process of education itself but also for providing the most possible comfort and safety for students and parents. This work was conducted to improve the transport services provided to the students in Saudi Arabia's schools. For this, the safety tracking and sensor system for school buses were designed and developed using a software application. This proposed system provides a way for the parents to track their children during their daily journeys to and from school using GPS, and notifies them before the arrival of the bus arrived at their doorstep. The application also notifies the school bus driver about absentee students. In addition, the system informs the bus driver through an SMS alert if there is a forgotten student inside the bus detected by the PIR sensor in the bus. The experiment result gave us more positive impact and higher expression of school buses need. Future work includes a full implementation of the sensor system will be achieved and tested. Therefore, we suggest that applying the tracking and sensor system and make the application applicable in all the schools of Saudi Arabia to achieve a high level of safety, security, and comfort for students and their families. 


\section{References}

[1] M. H. Sharif, I. Despot, and S. Uyaver, "A Proof of Concept for Home Automation System with Implementation of the Internet of Things Standards," Period. Eng. Nat. Sci., vol. 6, no. 1, pp. 95-106, Apr. 2018.

[2] H. H. O. Nasereddin and M. Faqir, "The impact of internet of things on customer service: A preliminary study," Period. Eng. Nat. Sci., vol. 7, no. 1, pp. 148-155, Apr. 2019.

[3] L. Katims, "High-tech school bus teaches students on the road," Educ. Dig., vol. 77, no. 2, p. 50, 2011

[4] Sabq: A student dies in a school bus (Arabic). [Online]. Available: https://sabq.org/Xs7cmK. [Accessed: 23-Dec-2018].

[5] "Four-year-old girl left alone in school bus dies | GulfNews.com." [Online]. Available: https://gulfnews.com/news/gulf/qatar/four-year-old-girl-left-alone-in-school-bus-dies-1.628394. [Accessed: 07-Oct-2018].

[6] P. A. Shinde, Y. B. Mane, and P. H. Tarange, "Real time vehicle monitoring and tracking system based on embedded Linux board and android application," in 2015 International Conference on Circuits, Power and Computing Technologies [ICCPCT-2015], 2015, pp. 1-7.

[7] M. Ghareeb, A. Bazzi, S. Abdul-Nabi, and Z. A.-A. Ibrahim, "Towards smarter city: clever school transportation system," Analog Integr. Circuits Signal Process., vol. 96, no. 2, pp. 261-268, Aug. 2018.

[8] “GPS (Global Positioning System) Definition.” [Online]. Available: https://techterms.com/definition/gps. [Accessed: 09-Oct-2018].

[9] A. A. Habadi and Y. S. AbuAbdullah, "Intelligent Safety School Buses System Using RFID and Carbon Dioxide Detection," in 2018 1st International Conference on Computer Applications Information Security (ICCAIS), 2018, pp. 1-7.

[10] K. Shaaban, A. Bekkali, E. B. Hamida, and A. Kadri, "Smart Tracking System for School Buses Using Passive RFID Technology to Enhance Child Safety," J. Traffic Logist. Eng., vol. 1, no. 2, pp. 191-196, 2013.

[11] S. Furniss, "Edulog's Technology Helps Get Saudi Arabian Girls to School, Provides 130+ Jobs in Missoula," Montana High Tech Business Alliance, 04-Jun-2015.

[12] A. Ahmed, E. Nada, and W. Al-Mutiri, "University Buses Routing and Tracking System," Int. J. Comput. Sci. Inf. Technol., vol. 9, no. 1, pp. 95-104, Feb. 2017.

[13] F. Assery, M. Alajmy, and Y. Albagory, "Smart Bus Transportation System for Fast Arrival Time to the Girls Campus at Taif University," vol. 13, no. 10, p. 4, 2018.

[14] F. Abdessemed, "An integrated system for tracking and control pilgrims shuttle buses," in Intelligent Transportation Systems (ITSC), 2011 14th International IEEE Conference on, 2011, pp. 384-389.

[15] J. Fraden, Handbook of modern sensors: physics, designs, and applications, 5th edition. Cham Heidelberg New York Dordrecht London: Springer, 2016. 